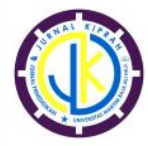

http://ojs.umrah.ac.id/index.php/kiprah

p-ISSN 2354-7278 | e-ISSN 2580-6947

\title{
Pengembangan Materi Morpho-Sytax Melalui Smart Chart
}

\author{
Caltira Rosiana* \\ Program Studi Pendidikan Bahasa Inggris, STKIP PGRI Nganjuk, Nganjuk, Indonesia
}

Pengiriman: 11/05/2021; Diterima: 21/06/2021; Publikasi: 29/06/2021

DOI: $10.31629 /$ kiprah.v9i1.3310

\begin{abstract}
Abstrak
Morpheme dan Syntax merupakan subjek perkuliahan yang wajib diampu oleh seluruh mahasiswa program studi pendidikan Bahasa Inggris, ironisnya, berdasarkan hasil observasi, 70\% mahasiswa tidak memiliki ketertarikan dalam pembelajaran ini karena diaggap sebagai momok yang menakutkan. Sulitnya memahami buku saintifik bahasa asing, dan kelangkaan pembaharuan materi pembelajaran menjadi kendala mahasiswa, mengakibatkan mahasiswa hanya menggantungkan pemahaman mereka kepada dosen dalam proses pembelajaran tatap muka. Situasi pandemi yang mengharuskan mahasiswa untuk belajar mandiri dengan buku induk morphemes dan syntax yang sulit dipahami, serta metode pembelajaran yang monotone membuat pembelajaran daring menjadi tidak efektif. Penelitian ini bertujuan mengembangkan materi tambahan Morpho-Syntax melalui smart chart bagi mahasiswa agar mudah dipahami dan dapat digabungkan dengan sumber pembelajaran lainnya. Untuk mencapai tujuan, peneliti menggunakan desain Penelitian dan Pengembangan dengan mengadopsi dan mengadaptasi dari Borg and Gall yang dalam tiga langkah, yakni analisis kebutuhan, desain pengembangan dan validasi produk. Peneliti melakukan studi pendahuluan, mendesain pemecahan masalah dan mengembangkan materi pelengkap sejak akhir Agustus 2020 lalu melalui beberapa tahapan sampai akhirnya peneliti berhasil memproduksi materi tambahan English Morpho-Syntax berdasar pada Smart Chart. Berdasarkan hasil trying out yang telah dilakuakan, pengembangan materi ajar melalui Smart Chart mendapatkan hasil bahwa 75\% mahasiswa dapat memahami pembelajaran Moprho-Syntax dengan baik.
\end{abstract}

Kata kunci: morpho-syntax; pengemangan materi; smart chart

\begin{abstract}
Morpheme and Syntax are the subjects must be learnt by all the students of English programs, ironically, based on observations, $70 \%$ of students have no interest in this learning because it is considered a difficult subject in English program. The obstacles of the students in learning Morpho-Syntax are the difficulty of understanding foreign language in scientific books, and limited material update, as the result, the student's only focus on their lecturer's explanation directly (offline class). But, the pandemic situations compel the students to study MorphoSyntax through core book independently, it was difficult to understand, the monotones online learning method was ineffective for the students. The goal of this study is developing additional Morpho-Syntax material through Smart Charts, it will make the student easy to master Morpho-Syntax material, and it is suitable to compare with others learning resources. To achieve the goal, the researcher uses Research and Development design which adopted and adapted from Borg and Gall in three steps, namely needs analysis, design development and product validation. Actually, the researchers had been conducted the preliminary studies, designed of learning and developed complementary materials since last August 2020. As the result, of the trying out which has been done this year, the Research and Development through Smart Charts shows that 75\% of students could understand Morpho-Syntax subject.
\end{abstract}

Keywords: morpho-syntax; smart chart; supplementary material

PENDAHULUAN

Demi mendukung program pemerintah dalam mewujudkan kampus merdeka, maka beberapa subjek pembelajaran dalam Program 
Studi pendidikan Bahasa Inggris harus dirampingkan, yakni menggabungkan dua subjek pembelajaran, Moprhemes dan Syntax menjadi Morpho-Syntax. Ilmu Morphome atau morphology, fokus kajiannya adalah tentang kata-kata yang diuraikan menjadi elemenelemen kecil yang bermakna yang secara linguistik disebut morfeme (Stebbins, 2007). Namun, syntax adalah studi tentang kalimat dan strukturnya, serta konstruksi dalam kalimat. Baik istilah sintaksis dan tata bahasa adalah tentang aturan kalimat (Stebbins, 2007). Yang perlu dijelaskan dengan jelas adalah sebenarnya sintaksis dan tata bahasa itu berbeda. Tata bahasa adalah seperangkat aturan untuk mengatur elemen bermakna ke dalam kalimat. Satu bagian tata bahasa disebut morfologi (internal), dan bagian lainnya disebut sintaks (eksternal). Dengan demikian, perlu perlakuakn khusus untuk menyajikan hal ini kepada mahasiswa, terutama saat pembelajaran daring. Pembelajaran daring dalam hal ini, tidak serta merta hanya menyajikan materi yang ada kepada mahasiswa, tetapi dosen juga wajib melakukan pengambangan diri untuk mencapai tujuan pembelajaran dan capaian pembelajaran dari Morpho-Syntax tersebut.

Para ahli linguistik menyatakan bahwa ilmu linguistik telah berkembang dari waktu ke waktu karena terminologi yang tidak jelas dari sifat bahasa (Nunn, 2006; Stebbins, 2007) Untuk menghindari evolusi negatif, deskripsi kebahasaan harus dirancang untuk mengikuti pemahaman kebahasaan terkait dengan perkembangan liguistik dimasa depan. Oleh karena itu, mahasiswa yang mempelajari linguistik harus mengetahui hakikat bahasa mulai dari bagian kecil linguistik seperti bunyi dan makna termasuk morfologi dan sintaksis (Banik, 2015). Pengertian bagian-bagian yang berkaitan dengan linguistik mengacu pada linguistik yang memperhatikan aspek tata bahasa (Spreng, 2012).

Kenyataanya, kajian linguistik bukan hanya tentang tata bahasa, cabang ilmu linguistik itu banyak dan perlu dipelajari, terutama Morfology dan Syntax. Morfology adalah ilmu yang mempelajari tentang pembentukan kata dan komposisi kata (Stebbins, 2007). Sedangkan syntax adalah ilmu yang mempelajari tentang pembentukan dan susunan frasa dan kalimat dari kata (Stebbins, 2007). Berdasarkan hasil observasi yang di lakukan kepada mahasiswa dalam tiga tahun terakhir, $80 \%$ mahasiswa sulit mempelajari buku induk Morphems dan Syntax, tanpa adanya penjelasan langsung dari dosen. Hal ini dikarenakan, kurangnya pemahaman mahasiswa terhadap kosa kata asing. Kemudian, pembelajaran daring yang monoton, yakni dosen menyajikan pembelajaran melalui persentasi online, hal hasil mahasiswa tidak akan mencapai target pembelajaran lebih dari $10 \%$.

Berdasarkan studi pendahuluan diatas, peneliti menemukan beberapa permasalahan yang berkaitan dengan materi pembelajaran, motivasi, dan pemahaman mahasiswa terhadap materi pembelajaran Moprhemes dan Syntax. Kelas linguistik yang terlibat dalam penelitian ini menggunakan buku Jim Miller sebagai buku induk atau buku wajib dalam mempelajari Syntax, namun kemudian buku ini tidak digunakan lagi karena deskripsi pelajaran tentang Morpho-Syntax pada silabus berbeda dengan isi buku Miller. Sayangnya, saat ini buku yang digunakan untuk pembelajaran Morpho-Syntax yang dinilai sesuai dengan silabus mata kuliah sulit ditemukan terutama di sekitar Nganjuk, Kediri, Jombang, Mojokerto dan Surabaya. Selain itu, materi Morpho-Syntax yang tersedia secara online pun terlalu umum bagi mahasiswa sehingga membuat mahasiswa kesulitan dalam mempelajari Morpho-Syntax. Siswa membutuhkan buku dan referensi yang lebih banyak dalam proses pembelajaran dan mencapai target pembelajaran (Rosiana, 2020b) agar membantu mahasiswa memahami materi secara efektif. Singkatnya, mata kuliah linguistik sering dianggap membosankan. Fakta ini mendorong dosen linguistik untuk merangsang motivasi belajar mahasiswa dengan mengembangkan materi MorphoSyntax yang paling tepat dan mengubah 
metode pembelajaran linguistik (Ziegler dkk., 2010).

Penelitian yang sama pernah dilakukan oleh (Saputri, 2018) pada Sekolah Menengah Kejuruan dengan melakukan analisa kesalahan yang digunakan siswa dalam hasil pekerjaan siswa dipandang dalam aspek linguistik. Penelitian serupa banyak digunakan, yakni dnegan melakukan analisa terhadap bagian sub skill dari aspek linguistik. Penelitian terdahulu yang telah dilakukan dalam subjek pembelajaran yang sama yakni minimnya penelitian lingistik yang berdasar pada Penelitian dan Pengembangan. Oleh karena itu, penelitian ini perlu dilakukan sebagai suatu inovasi dalam mempelajari cabang pembelajaran Linguistik termasuk Morphemes dan Syntax. Penelitian Pengembangan berasal dari Borg and Gall merupakan metode penelitian yang tepat dalam mengaplikasikan penelitian ini. Melalui Smart Chart, mahasiswa akan mudah mempelajari liguistik baik secara daring ataupun luring, serta menstimulasi proses berfikir mahasiswa dalam proses pembelajaran.

Pengambangan materi tambahan English Morpho-Syntax merupakan salah satu cara untuk menyelesaikan permasalahan mahasiswa terhadap pemahaman buku dalam bahasa asing. Pengembangan materi melalui hand out Morpho-Syntax sederhana tidak cukup untuk menstimulasi motivasi belajar mahasiswa. Penyajian materi pembelajaran melalui Smart Chart merupakan kunci keberhasilan proses pembelajaran Linguistik secara virtual. Smart Chart yang diadopsi dari Productive Reading Technique merupakan salah satu penyajian materi yang dapat menstimulasi proses berfikir kritis mahasiswa dalam proses membaca, karena memuat enam aktifitas penting (Rosiana, 2020a).

Menurut (Brown, 2006) pemahaman membaca dengan kegiatan observasi, interview, membaca, menguji/melakukan percobaan, dan mengevaluasi adalah kegiatan yang dapat meningkatkan daya ingat siswa terhadap materi. Selama proses pembelajaran, metode ini akan merangsang kemampuan berpikir mahasiswa. Untuk alasan tersebut, peneliti mengembangkan bahan bacaan tambahan tentang Morpho-Syntax. Sesuatu yang unik merupakan faktor terpenting dalam penelitian pengambangan (Liu, 2009; Rescorla \& Turner, 2015) maka materi yang dikembangkan dalam penelitian ini juga mempunyai keunikan tersendiri, yang dapat memberikan manfaat besar baik bagi mahasiswa, dosen dan instansi.

\section{METODE PENELITIAN}

Penelitian pengambangan dipandang sebagai desain yang paling tepat untuk penelitian ini karena digunakan untuk mengembangkan produk pendidikan (Ningrum dkk., 2016). Desain penelitian dan Pengembangan juga merupakan langkah yang tepat untuk megatasi berbagai masalah mahasiswa dalam subjek pembelajaran linguistik, terutama pada pembelajaran Morphems dan Syntax.

Desain penelitian dan pengembangan (R\&D) yang diadaopsi dari Borg and Gall. Peneliti melakukan adaptasi langkah-langkah yang ada menjadi lebih efisien, tanpa menghilangkan point penting dari penelitian ini. Secara umum penelitian pengembangan adalah proses untuk mengembangkan dan memvalidasi produk pendidikan (Borg \& Gall, 1984) yang dibentuk dalam serangkaian langkah (lihat Tabel 1). 
Tabel 1. Metode Penelitian

\begin{tabular}{l} 
Langkah Pertama = Studi analisa kebutuhan \\
Mahasiswa \\
a. Mengidentifikasi kekurangan fasilitas \\
pendidikan dan melakukan konfirmasi kepada \\
mahasiswa (untuk mengetahui materi yang \\
cocok dan kompetensi yang sesuai) \\
• Menganalisa materi , media dan fasilitas \\
pembelajaran \\
• Interview mahasiswa dan dosen linguistik \\
Menyebarkan kuisioner \\
Mendesain kisi-kisi dokumen pembelajaran \\
dan menyesuaikan target pembelajaran \\
\hline Langkah Kedua = Pengembangan materi \\
a. Melakukan desain pengembangan materi \\
ajar berdasarkan dua buku induk, yakni \\
moprholosgy dan syntax. \\
b. Memasukkan unsur Smart Chart dalam setiap \\
bab/chapter.
\end{tabular}

Populasi dalam penelitian ini adalah mahasiswa Jurusan Bahasa Inggris semester lima yang mengambil mata kuliah Morphosyntax pada program studi Bahasa Inggris tahun ajaran 2020/2021. Subjek uji coba sebanyak dua puluh lima siswa atau satu kelas, sehingga peneliti menggunakan teknik purposive sampling untuk mengumpulkan data. Subjek pelajaran uji coba produk tidak dipilih berdasarkan masalah mereka dalam belajar bahasa Inggris, tetapi dipilih berdasarkan minat mereka terhadap mata pelajaran dan nilai akademik mereka. Peneliti menggunakan teknik non-probability sampling untuk memastikan bahwa pengumpulan data selama proses pembelajaran efektif (lihat Tabel 2).
Tabel 2. Subjek Observasi

\begin{tabular}{llcc}
\hline No & Subjek Observasi & Jumlah & \multicolumn{1}{c}{ Data } \\
\hline 1. & Dosen Linguistik & 2 & Interview \\
& Mahasiswa & & \\
2. & $\begin{array}{l}\text { Program Studi } \\
\text { Bahasa Inggris }\end{array}$ & 27 & Kuisioner \\
& yang mengambil & & \\
& Perkuliahan \\
& English Morpho- \\
& Syntax \\
\hline
\end{tabular}

Untuk melekaukan desain penelitian, peneliti menggali data secara detail dan terarah melalui analisa kebutuhan mahasiswa, intrumen penelitian pengembangan materi berdasarkan Smart Chart, validasi produk Smart Chart dan dan desain produk akhir.

\section{Analisa kebutuhan mahasiswa}

Dalam melakukan penelitian pengembangan, dibutuhkan pra-penelitian yang digunakan sebagai bukti atau data empirik untuk melakukan sebuah pengembangan. Peneliti juga melakukan kegiatan ini dengan teliti dan seksama sebelum memutuskan untuk membuat penelitian pengembangan. Sementara itu, pra-penelitian merupakan kegiatan utama yang bertujuan untuk memperoleh informasi tentang permasalahan yang sebenarnya baik dari dosen maupun mahasiswa dalam konteks pendidikan pembelajaran. Analisis kebutuhan merupakan analisis kesimpulan dari dokumen pembelajaran yang digunakan sebagai dasar untuk mengembangkan suatu produk penelitian (Branch, 2009) juga menjelaskan bahwa analisis kebutuhan adalah cara untuk menemukan kemungkinan penyebab kesenjangan dokumen pembelajaran.

Kesenjangan yang dimaksud terjadi karena beberapa aspek yang terkait dengan pembelajaran tidak mencukupi, dapat berasal dari peserta didik, dosen atau dokumen pembelajaran (Branch, 2009). Tujuan dari menemukan gap dalam penelitian pengembanga ini adalah untuk mengidentifikasi dokumen (materi) 
instruksional yang tersedia bagi mahasiswa dan untuk mengidentifikasi kemampuan, pengalaman, preferensi, perangkat pembelajaran dan motivasi peserta didik terkait dengan materi pembelajaran (Branch, 2009).

\section{Instrumen Penelitian}

Instrumen penelitian diberikan kepada subjek observasi sebanyak 2 kali, sebelssetelases trying out. Selanjutnya, peneliti menggunakan wawancara terpandu atau wawancara semi terstruktur untuk semua mahasiswa dan dosen dalam penelitian ini. Jenis wawancara ini dipilih karena lebih terfokus dalam menjawab permasalahan yang ada (Latief, 2016). Wawancara terpandu merupakan model yang efektif bagi pewawancara untuk memahami data. Untuk mendapatkan data yang jelas, peneliti merancang kuisioner dengan respon "ya" dan "tidak" untuk mendapatkan informasi terkait tentang buku induk, lembar kerja mahasiswa dan fasilitas dalam proses pembelajaran. Hal ini dilakukan untuk mengetahui permasalahan materi ajar dan dipandang penting karena penentuan tujuan pembelajaran merupakan cara utama untuk menjawab permasalahan tersebut (Branch, 2009). Setelah mendeskripsikan masalah yang berkaitan dengan dokumen pembelajaran, peneliti menghasilkan tujuan sebagai tanggapan atas beberapa celah yang ditemukan.

Setelah dilakukan uji coba produk kepada mahasiswa, peneliti memberikan angket terbimbing untuk mengetahui pendapat, komentar, kritik, dan saran siswa terkait produk (materi tambahan Morpho-Syntax). Kemudian, mahasiswa diwawancarai untuk mengetahui lebih dalam tentang pendapat mereka tentang materi pengembangan yang telah dibuat. Setelah kuisioner dan wawancara diberikan dan hasilnya dikumpulkan, produk diperiksa kembali oleh pakar atau ahli Linguistik dnegan memberikan checklist untuk mengukur kualitas produk. Daftar periksa pakar atau ahli linguitik memiliki lima poin: bahasa yang digunakan pengorganisasian materi, tujuan instruksional, isi materi, dan desain peuugasan. Selanjutnya, wawancara dilakukan kepada dosen untuk mengetahui perspektif dosen tentang produk pengembangan. Terakhir, peneliti memperbaiki materi berdasarkan checklist, angket dan hasil wawancara.

\section{Pengembangan Materi English Morpho- Syntax Berdasar Pada Smart Chart}

Tujuan pengembangan bahan ajar adalah untuk mendeskripsikan strategi pembelajaran yang lebih efektif dan menstimulasi mahasiswa dalam proses pembelajaran (Sukman dkk., 2020). Sebelum melakukan pengembangan materi, peneliti merancang pengembangan materi berdasarkan standar kompetensi dalam kurikulum (KKNI) agar tidak terjadi gap antara materi yang dikembangkan dengan kompetensi siswa. Kemudian, peneliti mengembangkan bahan tambahan Morpho-Synatx untuk menstimulasi berpikir kritis mahasiswa berdasarkan hasil analisis kebutuhan dan kajian referensi yang yang telah diobservasi sebelumnya. Rancangan kegiatan didasarkan pada acuan studi yang dipandang sesuai dengan standar kompetensi dan kompetensi dasar silabus Morpho-Synatx dalam kurikulum (KKNI).

Materi Morpho-Synatx disajikan dalam bentuk Smart Chart, yang berarti dosen terlebih dahulu membarikan ringkasan materi linguistik dalam bentuk tabel atau grafik. Hal ini sangat efektif bagi mahasiswa dalam mempelajarai linguistik berikut dengan informasi detail lainnya. Berdasarkan tabel ataupun grafik tersebut, dosen dapat memberi tugas kepada mahasiswa berdasarkan proses berfikir kritis mahasiswa.

Selain itu, penyajian tugas dan kegiatan pembelajaran dihubungkan dengan kegiatan sehari-hari atau life skill. Hal ini akan meminimalisir kegiatan plagiasi yang di lakukan oleh mahasiswa.

\section{Validasi produk Pengembangan}

Tujuan validasi produk dari penelitian 
pengembanagn adalah untuk memastikan bahwa materi tambahan tersebut valid untuk diterapkan di kelas (Latief, 2016) Jadi, sebelum menggunakan materi pelengkap dalam konteks kelas yang sebenarnya, kuantitas dan kualitas bahan pelengkap dikonsultasikan kepada ahli karena kritik dan saran dari pakar materi linguistik sangat penting untuk perbaikan produk.

Produk penelitian ini divalidasi oleh Sujono, S.S. M.Pd. sebagai praktisi pendidikan. Beliau adalah dosen bahasa Inggris yang memiliki passion di bidang linguistik. Kemudian, peneliti menyempurnakan produk berdasarkan hasil validasi ahli sebelum diujicobakan pada konteks kelas yang sebenarnya.

\section{Produk Akhir}

Hasil validitas produk kedua, wawancara, dan kuisioner digunakan untuk merevisi dan menyempurnakan produk berupa bahan pelengkap morphosyntax. Revisi yang telah dilakukan sebelumnya berpengaruh besar dalam menentukan kualitas produk akhir. Jika produk yang direvisi tercapai, maka produk akhir secara resmi siap untuk dirilis. Sayangnya, peneliti tidak dapat mengimplementasikan produk akhir ke dalam konteks kelas yang sebenarnya karena waktu yang terbatas. Namun, dalam penelitian mendatang, peneliti akan melakukannya. menerapkan produk akhir untuk mengetahui apakah produk tersebut benar-benar dapat diterapkan pada proses pembelajaran.

\section{HASIL DAN PEMBAHASAN}

Pada bagian ini penulis memaparkan hasil penelitian dan pembahasan proses pengembangan materi Morpho-Syntax pelengkap untuk menstimulasi pemikiran kritis mahasiswa, yang disajikan dalam bentuk Hasil analisa kebutuhan mahasiswa dan Referensi pebelajaran, hasil pengembagan materi dan hasil validasi empirical

\section{Hasil Analisa kebutuhan Mahasiswa dan Referensi Pembelajaran}

Hasil analisis kebutuhan dalam penelitian pengembangan bahan ajar merupakan langkah awal yang harus dilakukan. Analisis kebutuhan bersumber dari angket dan hasil wawancara dari mahasiswa yang mengambil mata kuliah Morpho-Syntax dan juga dari hasil wawancara dosen. Untuk mengidentifikasi gap dan mengkonfirmasi audiens yang dituju, peneliti menganalisis dokumen pembelajaran melalui langkahlangkah induktif. Peneliti menganalisis masalah mahasiswa mulai dari aspek umum hingga aspek spesifik.

Peneliti memberikan enam pertanyaan dan mencatat informasi penting tersebut. Hasilnya menyiratkan bahwa dua puluh lima siswa tidak dapat menikmati belajar linguistik. Hal ini dikarenakan materi yang diberikan sulit untuk dipahami dan karena kegiatan kelas hanya berupa presentasi kelas. Melalui hasil kesimpulan observasi dan try out, banyak mahasiswa mengalami kendala dalam mempelajari linguistik khususnya mata pelajaran Morpho-Syntax. Meskipun mahasiswa mempelajari mata pelajaran linguistik sebelum mereka berada di semester lima, sayangnya mahasiswa masih menganggap linguistik sebagai hal yang sulit untuk dipelajari. Hal ini terjadi karena buku referensi linguistik menggunakan memuat istilah-istilah sulit dan membuat mahasiswa bosan untuk membacanya. Oleh karena itu, sebagian besar mahasiswa lebih suka mengambil materi linguistik dari sumber online yang sayangnya juga terlalu umum dan hanya memiliki sedikit penjelasan rinci tentang subjek tersebut. Mengetahui permasalahan tersebut, peneliti merancang kuisioner. Bentuk respon "ya dan tidak" membantu peneliti mendapatkan jawaban yang jelas. Dua puluh Lima siswa diminta menjawab pertanyaan yang difokuskan pada masalah siswa dalam keterampilan linguistik. Isi kuisioner adalah sebagai berikut 
Table 3. Respons "ya” dari Instruksional Dokumen Pembelajaran

\begin{tabular}{|c|c|c|c|}
\hline \multirow[t]{3}{*}{$\begin{array}{l}\mathbf{n} \\
\mathbf{o}\end{array}$} & \multirow[t]{3}{*}{ Pertanyaan } & \multicolumn{2}{|c|}{$\begin{array}{c}\text { Instruksinal } \\
\text { Dokumen }\end{array}$} \\
\hline & & \multicolumn{2}{|c|}{ Morpho-Syntax } \\
\hline & & Jumlah & Persentase \\
\hline 1. & $\begin{array}{l}\text { Buku } \\
\text { Mophemes dan Syntax } \\
\text { menarik }\end{array}$ & 5 & $18.5 \%$ \\
\hline 2. & $\begin{array}{l}\text { Memahami isi Buku } \\
\text { dengan menggunakan } \\
\text { Kamus }\end{array}$ & 10 & $37 \%$ \\
\hline 3. & $\begin{array}{l}\text { Memahami isi Buku } \\
\text { tanpa menggunakan } \\
\text { Kamus }\end{array}$ & - & $0 \%$ \\
\hline 4. & $\begin{array}{l}\text { Memahami isi Buku } \\
\text { Morpheme dan Syntax }\end{array}$ & $10 \%$ & $37 \%$ \\
\hline 5. & $\begin{array}{lr}\text { Buku } & \text { Referensi } \\
\text { Mendukung } & \text { Sesuai } \\
\text { Dengan Tugas, Tes dan } \\
\text { UAS }\end{array}$ & 15 & $55.5 \%$ \\
\hline
\end{tabular}

Dari hasil angket diatas terlihat jelas bahwa sebagian besar mahasiswa menerima buku Referensi sebagai dokumen pembelajaran dalam proses pembelajaran. Hasil penelitian menunjukkan bahwa $18.5 \%$ mahasiswa menyatakan bahwa buku referensi yang tersedia kurang menarik karena menggunakan bahasa saintifik dan sulit dipahami. Selain itu, buku tersebut sulit dipelajari, dimengerti dan dipahami karena bersifat soft file. Inronisnya, tidak ada mahasiswa yang dapat memahami isi buku referensi tanpa kamus, meskipun mereka adalah mahasiswa jurusan pendidikan bahasa Inggris. Dari segi pemahaman keterampilan linguistik, sekitar 10 siswa dapat memahami pelajaran dari pembelajaran buku referensi morphosyntax. Saat ditanya kelayakan materi pada tes formatif, lima belas siswa (55.5\%) menjelaskan bahwa materi pada buku referensi Morpho-Syntax hampir sesuai untuk membantu mereka dalam tes formatif.
Tabel 4. Sub-Skil reading dari Materi Buku Induk

\begin{tabular}{llcc}
\hline n & \multicolumn{1}{c}{ Pertanyaan } & \multicolumn{2}{c}{$\begin{array}{c}\text { Instruksinal } \\
\text { Dokumen }\end{array}$} \\
\cline { 3 - 4 } & & \multicolumn{2}{c}{ Morpho-Syntax } \\
\cline { 3 - 4 } & & $\begin{array}{c}\text { Jumlah } \\
\text { Persentas } \\
\text { 1. }\end{array}$ & Pemahaman kosa kata \\
\hline 2. & Pemahaman kalimat & 12 & $37 \%$ \\
\hline 3. & Pemahaman Paragraf & 13 & $48.1 \%$ \\
\hline 4. & $\begin{array}{l}\text { Menyimpulkan } \\
\text { Informasi }\end{array}$ & 8 & $29.6 \%$ \\
\hline 5. & $\begin{array}{l}\text { Mengevaluasi masalah } \\
\text { dalam text }\end{array}$ & 9 & $33.3 \%$ \\
\hline 6. & $\begin{array}{l}\text { Memahami Informasi } \\
\text { didalam text }\end{array}$ & 1 & $3.7 \%$ \\
\hline
\end{tabular}

Tabel 3 menunjukkan bahwa kurang dari $50 \%$ siswa memahami materi morphosyntax, dan hanya $3.7 \%$ memahami materi dengan pemahaman kalimat sedangkan $48.1 \%$ responden memahami menggunakan pemahaman Paragraf. Selain itu, hanya $32 \%$ siswa yang dapat menyimpulkan informasi faktual dari teks dan hanya $29.6 \%$ siswa yang dapat mengevaluasi ekspresi dalam suatu konteks. Dengan demikian, hal ini menunjukkan bahwa sebagian besar siswa yang terlibat dalam penelitian ini perlu mempelajari cara mengidentifikasi ekspresi yang mengandung fakta dan opini, bukti, dan definisi. Namun hanya seorang siswa (3.7\%) yang mengerjakan tugas tepat waktu. Hal ini terjadi karena siswa jarang mendapat tugas yang memiliki tenggat waktu, sehingga membutuhkan lebih banyak latihan. Meskipun aspek ini tidak termasuk pada materi, namun hal ini dapat digunakan untuk memberikan kegiatan yang mendukung kurikulum standar (KKNI) untuk merangsang berpikir kritis siswa.

Hasil wawancara dosen juga menunjukkan masih adanya kendala dalam pembelajaran Morpho-Syntax, meskipun pembelajaran dilakukan berdasarkan kurikulum standar. Permasalahan tersebut terjadi karena buku yang dianggap sudah tua dan perlu update serta buku referensi untuk mata pelajaran kebahasaan terlalu sulit dipelajari oleh siswa karena sebagian besar 
berbentuk teks panjang sehingga kurang menarik bagi siswa. Penyebab lainnya adalah karena jarangnya dosen memberikan pelajaran tentang morfosintaks pada mata pelajaran kebahasaan yang mengakibatkan pengetahuan Morpho-Syntax mahasiswa kurang. Selain itu, mahasiswa juga kesulitan menyelesaikan tugas tepat waktu yang disebabkan oleh tidak adanya deadline yang diberikan oleh dosen

\section{Hasil Pengembangan Materi}

Pengembangan materi ajar dibuat berdasarkan analisis kebutuhan yang diperoleh dari angket siswa, wawancara guru, dan analisis buku. Semua sumber tersebut diadopsi dari berbagai sumber seperti lingkungan sosial, internet dan buku kemudian dimodifikasi oleh peneliti. Semua sumber pembelajaran diadopsi dan diadaptasi dengan buku referensi Morphosyntax. Setelah proses pemilihan materi, langkah selanjutnya adalah mengembangkan materi yang memiliki tingkat kesulitan yang disesuaikan dengan mahasiswa. Materi tersebut juga dirancang untuk memotivasi mahasiswa, merangsang pemikiran kritis mahasiswa dan membantu mereka untuk mempelajari morfosintaks dengan lebih baik. Peneliti mengurangi jumlah materi yang dibutuhkan tingkat daya ingat dan mengembangkan materi yang difokuskan pada tugas di tingkat berpikir kritis.

\section{Hasil Validasi Produk}

Produk hasil validasi ahli bermanfaat untuk merevisi dan menyempurnakan produk. Validatornya adalah Dosen STKIP PGRI Nganjuk dan merupakan Spesialis Linguistik. Validasi ahli dilakukan pada bulan Agustus 2020. Dalam proses validasi ahli, checklist yang terkait dengan aspek produk dikembangkan oleh peneliti dan diberikan kepada validator. Aspek pertama yang diteliti adalah bahasa yang digunakan mengacu pada teks atau percakapan yang digunakan dalam materi morfosintaks tambahan. Hasil penelitian menunjukkan bahwa bahasa yang digunakan dalam produk sudah baik karena diketik dengan baik dan rapi meskipun masih ditemukan kesalahan ketik. Font pada materi morphosyntax tambahan dinilai sangat baik karena dapat dipahami dalam hal jenis dan ukuran font. Peneliti menggunakan "Comic Sans MC" ukuran sepuluh. Hasil validasi juga mengimplikasikan bahwa pengertian bahasa yang digunakan dalam produk sudah sesuai dengan minat mahasiswa, dan kemampuan mahasiswa dalam memahami materi pelengkap dan tata bahasa yang digunakan.

Dari segi pengorganisasian materi, hasil validasinya sama dengan bahasa yang digunakan. Penyusunan materi dalam produk ini mudah diakses oleh dosen dan mahasiswa. Selain itu, pengorganisasian material dalam produk ini mengacu pada metode Productive Reading Technique yang menggabungkan beberapa aspek unik (smart key, my outside thinking, and crazy fact). Penyusunan materi yang diatur dalam teks juga dinilai sesuai untuk merangsang minat siswa selama proses pembelajaran dan merangsang berfikir kritis mahasiswa.

Validasi tujuan pembelajaran pada materi tambahan Morpho-Syntax juga memperoleh hasil yang baik karena tujuan pembelajaran cukup jelas. Pertama, tujuan pembelajaran yang konsisten untuk merangsang pemikiran kritis siswa dan siswa dapat mengikuti pembelajaran. Senada dengan hal tersebut, (Kartika \& Mubarok, 2017) juga menyatakan bahwa pembelajaran yang sederhana dan jelas membuat siswa lebih mudah memahami apa yang harus mereka lakukan dalam proses pembelajaran.

Dengan adanya Smart Chart, dapat membantu mahasiswa untuk memahami buku induk linguistik yang memiliki tata bahasa linguistik yang sulit. Selanjunya, dalam desain tugas validasi memiliki beberapa variabel: teks, kosakata, pertanyaan pemahaman, tinjauan tata bahasa, dan aktivitas. Teks materi tambahan morpheme dan syntax secara umum bagus. Produk menampilkan materi dengan berbagai teks dan tugas kinerja. Selanjutnya, grammar review bertujuan untuk memberikan struktur yang bermakna yang menunjukkan tidak menyajikan grammar seperti pada 
metode grammar translation (GTM). Bagian ini dipandang relevan dan sesuai dengan isi materi. Itu juga bagus karena contoh yang tepat digunakan sebagai model struktur tata bahasa yang bermakna.

Aktivitas yang disajikan dalam produk juga sesuai dengan proses pembelajaran dan mendapatkan hasil validasi yang sangat baik. Fokus pada tingkat berpikir kritis untuk mengintegrasikan pengetahuan siswa dan bahasa target siswa dengan melakukan analisis, menunjukkan perbedaan, meringkas dan sebagainya membuat siswa menjadi lebih aktif dan kreatif dalam proses pembelajaran.

Pengembangan materi Morpho-Syntax melalui Smart Chart lebih efisien untuk memahami pembelajaran linguistik, baik dalam penyampaian materi, pemberian, penyajian materi dan pemberian feed back pembelajaran. Dalam penyampaian materi Smart Chart menyajikan point-point penting yang telah disusun dosen dalam sebuah grafik, sehingga mahasiswa mudah mempelajari linguistik baik secara virtual ataupun luring. Berikut perbandingan Buku induk MorphoSyntax (Gambar 1) dan Desain Smart Chart (Gambar 2)

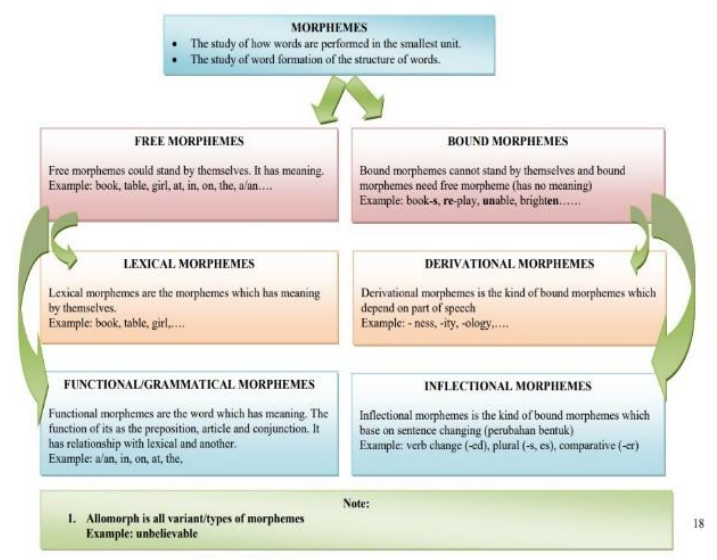

Gambar 1. Desain Smart Chart

Hal ini juga memotivasi mahasiswa dalam mempelajari dan memahami linguistik dalam proses berfikir kritis. Stimulasi berfikir kritis ini di dapat mahasiswa dari proses penyelesaian masalah yang diberikan oleh dosen dalam pemberian tugas. Disamping itu, validasi empirik dari produk pengembangan ini juga mendapatkan respon positif baik dari internal validasi dan eksternal validasi. Tentu saja hal ini membutuhkan motivasi dosen untuk melakukan perubahan dengan proses merangkum dan membuat desain Smart Chart di setiap sebelum melakukan proses pembelajaran. Berikut contoh tampilan materi English Morphemes berdasarakan buku induk (gambar 2)

\section{A word and its parts: roots, affixes and their shapes}

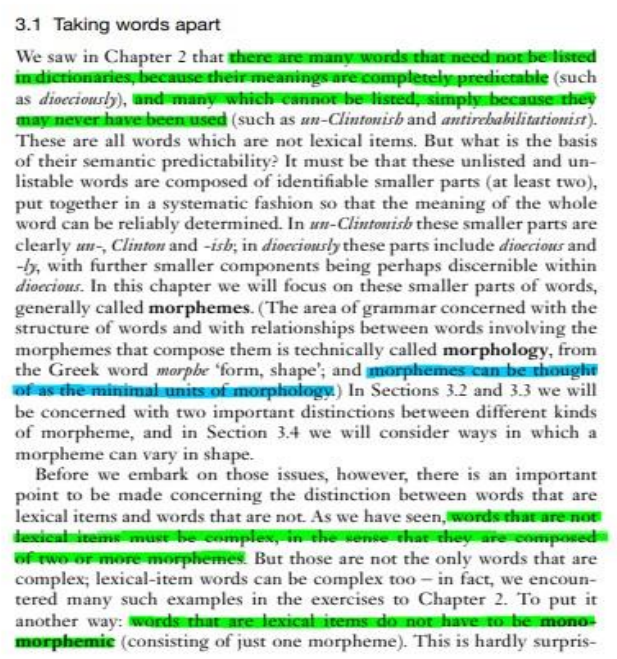

Gambar 2. Buku Induk Morpheme

Penelitian ini diarapkan bermanfaat bagi dosen, mahasiswa dan institusi. Bagi dosen, penelitian ini diharapkan memberi semangat untuk dosen dalam berinovasi dan produktif untuk membuat materi pembelajaran baik secara luring ataupun daring. Bagi mahasiswa, penelitian ini diharapkan dapat memudahkan mahasiswadalam proses pembelajaran, dan memotivasi mahasiswa untuk memiliki minat dalam pembelajaran linguistik. Bagi institusi, penelitian ini diharapkan dapat menjadi salah satu sumber pembelajaran. 


\section{KESIMPULAN}

Materi pelengkap Morpho-Syntax berdasarkan Smart Chart memiliki beberapa bagian antara lain sampul, kata pengantar, wacana buku, pemetaan buku, dan daftar isi, serta materi utama yang dikembangkan menjadi empat bab. Bab-bab tersebut meliputi analisis struktur kata, alomorf bebas dan terikat, morfem infleksi dan turunan, serta kategori \& fungsi kata.

Bagi para dosen dan mahasiswa, materi pelengkap ini dapat digunakan dalam kegiatan perkuliahan untuk pembelajaran kebahasaan bagi mahasiswa khususnya untuk meningkatkan kemampuan Pemahaman mahasiswa dalam subjek Linguistik. Produk ini juga dapat digunakan untuk membantu dosen dalam menyediakan materi yang sesuai dengan kebutuhan mahasiswa dan kurikulum standar. Apalagi produk ini hanya salah satu alternatif untuk para dosen dan mahasiswa untuk membantu proses pembelajaran. Selain itu, materi pelengkap English Morpheme dan Sytanx dapat terus di kembangkan dan dilengkapi dnegan informasi, pemberian kasus dan contoh-contoh yang lebih menantang, agar dapat menstimulasi proses berfikir kriis mahasiswa pada level yang lebih tinggi.

\section{REFERENSI}

Banik, R. L. (2015). Morphology and Growth (hal. 43-89). Springer, Cham. https://doi.org/10.1007/978-3-31914133-6_3

Borg, W. R., \& Gall, M. D. (1984). Educational Research: An Introduction. British Journal of Educational Studies, 32(3), 274. https://doi.org/10.2307/3121583

Branch, R. maribe. (2009). Instructional Design: The ADDIE Approach - Robert Maribe Branch - Google Buku. https://books.google.co.id/books?hl=id\&l $\mathrm{r}=\& \mathrm{id}=\mathrm{mHSwJPE} 099 \mathrm{EC} \&$ oi $=$ fnd $\& p g=P$ R3\&dq=Branch, + R.M.+2009.+Instructio nal+Design:+the+ADDIE+approach.+De partment+of+Educational+Psychology+a nd+Instructional+Technology+Universit $\mathrm{y}+$ of + Georgia\%3B+New+York\&ots=Jp
WpDEwT71\&sig

Brown, D. H. (2006). Principles of Language Learning and Teaching. San Fransisco State University. mozextension://94c2d8e2-9b42-452a-a23b830ce00e6862/enhancedreader.html?openApp\&pdf $=$ https $\% 3 \mathrm{~A} \% 2$ F\%2Fd1wqtxts1xzle7.cloudfront.net\%2F 40433526\%2F_H._Douglas_Brown__Pri nciples_of_language_learningBookZZ.or g-with-cover-

page.pdf\%3FExpires\%3D1620619099\% 26Signat

Kartika, P. C., \& Mubarok, I. W. (2017). Istilah Asing Produk Bahasa Suroboyoan Sebagai Bahan Pembelajaran Kearifan Lokal Kota Surabaya: Kajian Sosiolinguistik. In Insani Wahyu Mubarok. Istilah Asing .... Halaman (Vol. 2, Nomor 1). http://jurnal.unmuhjember.ac.id/index.ph $\mathrm{p} / \mathrm{BB} /$ article/view/647

Latief, M. A. (2016). Reliability of Language Skills Assessment Results. Jurnal Ilmu Pendidikan, $8(3)$. https://doi.org/10.17977/JIP.V8I3.562

Liu, C.-S. L. (2009). The positive morpheme in Chinese and the adjectival structure. https://doi.org/10.1016/j.lingua.2009.06.0 01

Ningrum, A. S. B., Latief, M. A., \& Sulistyo, G. H. (2016). The Effect of Mind Mapping on EFL Students' Idea Development in Argumentative Writing across Gender Differences and Learning Styles. Dinamika Ilmu, 16(1), 149. https://doi.org/10.21093/di.v16i1.296

Nunn, R. (2006). The Pragmatics of Cooperation and Relevance for Teaching and Learning. http://www.linguistics

Rescorla, L., \& Turner, H. L. (2015). JSLHR Research Article Morphology and Syntax in Late Talkers. https://doi.org/10.1044/2015_JSLHR-L14-0042

Rosiana, C. (2020a). Designing English Material Based On Productive Reading Technique To Teach English Subject For Non-English Students. Dharma Pendidikan, 15(1), 34-51. https://journal.stkipnganjuk.ac.id/index.p $\mathrm{hp} / \mathrm{jdp} /$ article/view/55

Rosiana, C. (2020b). Productive Reading Activity Dalam Mempelajarai Sosiologi Dan Linguistik. Historis : Jurnal Kajian, 
Penelitian dan Pengembangan Pendidikan Sejarah, 5(2), 129-135. https://doi.org/10.31764/historis.vXiY.34 23

Saputri, N. L. (2018). Morphological and Syntactical Error Analysis on The Students' Descriptive Composition of Private Vocational High School. Scope: Journal of English Language Teaching, $1(02)$,

174. https://doi.org/10.30998/scope.v1i02.135 3

Spreng, B. (2012). Viewpoint Aspect in Inuktitut: The Syntax and Semantics of Antipassives Syntax and Semantics of Progressives in Swabian View project. https://www.researchgate.net/publication/ 268301766
Stebbins, J. R. (2007). The Evolution of Evolutionary Linguistics. Colorado Research in Linguistics, 20. https://doi.org/10.25810/vefc-nw72

Sukman, S., Mistar, J., \& Fikri, D. (2020). The Differences in Reading Skills between Auditory Learners and Visual Learners | SUKMAN | Jurnal Penelitian, Pendidikan, dan Pembelajaran. http://www.riset.unisma.ac.id/index.php/j p3/article/view/8262

Ziegler, A., Ogurreck, M., Steinke, T., Beckmann, F., Prohaska, S., \& Ziegler, A. (2010). Opportunities and challenges for digital morphology. In Biology Direct (Vol. 5, Nomor 1, hal. 45). BioMed Central. https://doi.org/10.1186/17456150-5-45 